\title{
27 NEW WORDS AND OLD BOOKS: CHALLENGING CONVENTIONAL DISCOURSES ABOUT DOMAIN AND THEORY IN INFORMATION SYSTEMS RESEARCH
}

\author{
Bonnie Kaplan \\ Yale Center for Medical Informatics \\ Kaplan Associates \\ Hamden, $C T$ \\ U.S.A. \\ Lynette Kvasny \\ School of Information Sciences and Technology \\ Pennsylvania State University \\ University Park, PA \\ U.S.A. \\ Steve Sawyer \\ School of Information Sciences and Technology \\ Pennsylvania State University \\ University Park, PA \\ U.S.A. \\ Eileen M. Trauth \\ School of Information Sciences and Technology \\ Pennsylvania State University \\ University Park, $P A$ \\ U.S.A.
}

\begin{abstract}
In this panel, we address the question: "How does information systems (IS) research in nonbusiness domains push the IS field forward?" We pursue this question by focusing on the contemporary intellectual discourse of our community regarding appropriate domains, the sources of theory, and the common levels of analysis in IS research. The commentary of the panelists is focused on expanding the discourse by discussing our

The original version of this chapter was revised: The copyright line was incorrect. This has been corrected. The Erratum to this chapter is available at DOI: 10.1007/978-0-387-35634-1_28


empirical work in a wide range of sectors and at different levels of analysis. We expand the scholarly discourse on the value of theories by acknowledging that, while various theories (generally social theories) are typically drawn into the IS community, there is an increasing effort to extend these theories to better account for the effects of using ICT and IS. Increasingly, IS scholars are developing theories directly out of their empirical work on the uses of ICT and IS.

\section{OVERVIEW}

In this panel, we address the question: "How does information systems (IS) research in nonbusiness domains push the IS field forward?" We do this by highlighting three aspects of the intellectual discourse of our community:

1. The discourse about appropriate domains for IS research,

2. The discourse about the sources of theory in IS research, and

3. The discourse about levels of analysis in IS research.

Much of the discourse in the contemporary IS literature about the uses of information and communication technology (ICT) has been framed by studies carried out within a relatively small range of organizational types and sectors. For instance, the typical focus on contemporary IS research is in large, privatesector organizations. While there is a longstanding presence of other domains (such as health care, public administration, and small-to-medium enterprises SMEs) the dominant venue of theorizing the roles of ICT in IS has been the Fortune 500 organization (Lucas 1999; Swanson and Ramiller 1993).

However, as it has frequently been pointed out at previous IFIP WG8.2 meetings, there is an ever-increasing need for research that draws on other domains and at differing levels of analysis from the organization or work-group (Kaplan et al. 1997; Walsham 2000). For example, issues familiar to IFIP WG8.2 members regarding the roles of IS in organizations are also found in domains such as health care (Kaplan 2001; Kaplan and Shaw 2002), yet there is relatively little crossover among these two communities despite their similarities.

With respect to levels of analysis, increased attention to society and community interests is extending the boundaries of IS research from business organization settings into the community where people live, leading to increased analysis of societal impacts. For example, community informatics (Kvasny 2002; Romm and Taylor 2000) focuses on the provision and uses of ICT resources and 
tools whose uses enable communities to pursue their goals in such areas as local economic developments, cultural affairs, civic activism, electronic democracy, self-help, advocacy, and cultural enhancement.

The value of combining both new domains for research and multiple levels of analysis is evident in the value of cross-cultural IT studies (Trauth 2001). Cross-cultural studies have repeatedly identified the need to reexamine underlying assumptions about IS development, introduction, and use when systems developed in one cultural context are moved into another (Avgerou 2001; Trauth 2001).

There are at least two advantages to increased attention by IS researchers to domain and level-spanning research. First, research communities whose work is built on looking across sectors are more likely to be able to highlight pertinent issues and opportunities related to the continued growth in, reliance on, and increased pervasiveness of ICT. For example, there is much that could be learned from meta-analyses and other means of combining results from different studies to increase the level of generality and develop theory across different domains, levels of analysis, or other boundaries. Second, theories of, and analytic techniques for studying, ICT and IS would be valued by many other research communities (Baskerville and Myers 2002). This is particularly important for those theories and techniques that focus on cross-domain and cross-level efforts (MacKenzie and Wajcman 1999).

In this panel, we focus on expanding the discourse by discussing our empirical work in a wide range of sectors and at different levels of analysis. We expand the scholarly discourse on the value of theories by acknowledging that, while various theories (generally social theories) are typically drawn into the IS community, there is an increasing effort to both extend these theories to better account for the effects of using ICT and IS. Moreover, there is a growing focus on developing theories directly out of this work. We believe these theories reflect a greater degree of conceptualization around IS and ICT and that these emerging theories can be applied to other domains within IS research.

\section{ORGANIZATION OF THE PANEL}

After a brief overview of the panel objectives and scope, panelists will discuss ways in which their work contributes to (1) broadening the discourse about the usual and proper domains for IS research and (2) broadening the discourse about theory development from within the ranks of the IS community. While it may seem to be presumptive to highlight a theory-building agenda, we do so to emphasize the potential for significant contributions in pushing forward a deeper characterization of the socio-technical nature of ICT uses and what is 
meant by IS. After panelists' comments, we pose discussion questions concerning implications of focusing on theory development and widening the domain of discourse, such as:

1. If one accepts the need to expand the boundary or level of analysis of IS research, what are the implications for publishing this broader work? What happens if IS work is perceived more broadly than MIS journal editors currently value? What if the received wisdom is that premier IS journals may not welcome this type of broader IS work?

2. Does conducting research in different organizational types and sectors enable one to test extant IS theories in a new context? Does this mean that scholars can explore the limitations and unstated assumptions embedded in extant theory, as well as confirm prior knowledge? To what extent should work in other sectors involve theory testing versus theory generation?

3. Does studying different social and cultural contexts help expose the ways in which other social factors such as professional affiliation, personal identity, social origin, current social position and social status, race, ethnicity, gender, and sexuality shape the ways in which ICT and IS are experienced and understood. Do the communities that we study locate themselves within new discourses? Do they express novel metaphors for conceptualizing IT?

\section{PANELISTS}

Bonnie Kaplan will discuss the computer as Rorschach. Looking across several of her studies-yet another level of analysis - suggests that medical informaticians, clinicians, and administrators all see something different when they see computers. Moreover, different individuals and groups of individuals view the same computer application differently, illustrating psychologist Robert F. Bayles' observation that the computer functions as a Rorschach ink blot test (Nelson 1974, p. 9). This theoretical lens is little explored in information systems research. Sherry Turkle elaborates on the computer as a projective device through her studies of children, teen video game players, computer home hobbyists, and artificial intelligence researchers (Turkle 1980, 1984, 1995). Case examples in one domain (medical informatics) at individual and group levels of analysis, across a variety of different kinds of ICT applications, give meat to the theory for IS, including implications for research, design, and management. (Bonnie can be reached by e-mail at Bonnie.Kaplan@Yale.edu.) 
Lynette Kvasny is developing a concept of "digital inequality" through her study of community technology initiatives that serve low-income, predominantly African American communities in urban cities (Kvasny 2002). Digital inequality is social stratification that results from the unequal ability to adopt, adapt, and use information and communication technologies to improve life chances. Parsing this definition, social stratification results from the unequal distribution of valued resources, with the most privileged individuals or groups enjoying a disproportionate amount of property, power, or prestige. Life chances are those events that form the most important opportunities, achievements, and experiences in life such as physical and mental health, socially valued occupations, and educational opportunities (Tumin 1985)

This research adopts a critical perspective, and extends our understanding of the ways in which IT shapes and is shaped by social inequality. It is a social stratification approach to IS research that explores the intersection of IT, ethnicity, and socio-economic status to describe the contours of social groups, to explain the process by which individuals are allocated into different social and economic outcomes, and to uncover the institutional mechanisms by which social inequality is generated and maintained. (Lynette can be reached by e-mail at lkvasny@ist.psu.edu.)

Steve Sawyer is focused on theorizing what are the technical characteristics of social structures. This theorizing allows for two insights that extend the contemporary uses of social network theory. First, a focus on technical characteristics of social structures helps identify what characteristics of a technical artifact get involved in developing and shaping social networks. For example, a structural analysis can help highlight that structures of social interaction tend to form around issues of technical complexity (such as data integration). It can also highlight the ways in which various elements of the organizations learn of technical issues. Second, such a perspective provides a means to interpret socio-technical structures in contrast to the more commonly used project, process, and organizational structures. For example, a structural analysis of social interactions in an enterprise systems implementation suggests that users are but loosely connected to the people and units who are making significant design and installation decisions (Sawyer 2001). (Steve can be reached by e-mail at sawyer@ist.psu.edu.)

Eileen Trauth will discuss her emergent theory about underrepresented groups in the IT profession. Her work is currently focused on gender and participation in the IT labor force. This theory uses the lens of individual differences (Trauth 2002) to examine field study data about the ways in which women react in individual ways to the variety of societal influences on (1) their gender identity, (2) the gender shaping of IT, and (3) their subsequent decisions with respect to participation in the IT profession. She situates her discussion at 
the cross-cultural level of analysis. That is, individual women react to societal influences in different ways and develop different career paths in response to the ways in which they respond to a variety of cultural messages about gender and IT work. She came to be engaged in this theory development work when she found that the dominant, existing theories were insufficient to enable her to interpret and explain her field data. Thus, her work exemplifies theory development at the cross-cultural level of analysis. (Eileen can be reached by e-mail at etrauth@ist.psu.edu.)

\section{REFERENCES}

Avgerou, C. Information Systems and Global Diversity. Oxford: Oxford University Press, 2002. Baskerville, R., and Myers, M. "Information Systems as a Reference Discipline," MIS Quarterly (26:1), March 2002, pp. 1-14.

Kaplan, B. "Evaluating Informatics Applications-Social Interactionism and Call for Methodological Pluralism," International Journal of Medical Informatics (64), 2001, pp. 3956.

Kaplan, B., Sawyer, S, Trauth, E., and Baskerville, R. "Broadening the Basis of IS Research," panel at OASIS 97: Exploring New Ideas, Methods, and Problems in Information Systems Research (sponsored by IFIP WG 8.2), December 1997.

Kaplan, B., and Shaw, N. T. "People, Organizational, and Social Issues: Evaluation as an Exemplar," in R. Haux and C. Kulikowski (eds.), Yearbook of Medical Informatics. Stuttgart: Shattuer, 2002, pp. 71-88.

Kvasny, L. "A Conceptual Framework for Studying Digital Inequality," in R. Ramsower and J. Winston (eds.), Proceedings of the Eighth Americas Conference on Information Systems, Dallas, Texas, August 9-11, 2002, pp. 1798-1805.

Lucas, H. "The State of the Information Systems Field," Communications of the AIS (1:5), 1999, pp. 1-6.

MacKenzie, D., and Wajcman, J. The Social Shaping of Technology. Philadelphia: Open University Press, 1999.

Nelson, T. Computer Lib/Dream Machines (1 ${ }^{\text {st }}$ ed.). Millerton, NY: Aperture, 1974.

Romm, C., and Taylor, W. "Community Informatics: The Action, Reaction, Integration Model," in M. Chung (ed.), Proceedings of the Americas Conference on Information Systems, Long Beach, California, August 10-13, 2000, pp.1675-1680.

Sawyer, S. "Socio-Technical Structures in Enterprise Information Systems Implementation: Evidence from a Five-Year Study," in Proceedings of the 2001 IEEE EMS International Engineering Management Conference, Albany, NY, 2001, pp. 172-178.

Swanson, E., and Ramiller, N. "Information Systems Research Thematics: Submissions to a New Journal," Information Systems Research (4:4), 1993, pp. 299-330.

Trauth, E. M. "Odd Girl Out: An Individual Differences Perspective on Women in the IT Profession," Information Technology and People, Special Issue on Gender and Information Systems (15:2), 2002, pp.

Trauth, E. M. "The Pursuit of Information Technology in Context," Keynote Speech, Australasian Conference on Information Systems, Coffs Harbour, Australia, December, 2001.

Tumin, M. Social Stratification: The Forms and Functions of Inequality. Englewood Cliffs, NJ: Prentice-Hall, 1985.

Turkle, S. "Computer as Rorschach," Society (17:2), 1980, pp. 15-24. 
Turkle, S. Life on the Screen: Identity in the Age of the Internet. New York: Simon and Schuster, 1995.

Turkle, S. The Second Self: Computers and the Human Spirit. New York: Simon and Schuster, 1984.

Walsham, G. "Globalization and IT: Agenda for Research," in R. Baskerville, J. Stage, and J. I. DeGross (eds.), Organizational and Social Perspectives on Information Technology. Boston: Kluwer Academic Publishers, 2000, pp. 195-210. 